\title{
Caudal appendage-deafness syndrome
}

INSERM

\section{Source}

INSERM. (1999). Orphanet: an online rare disease and orphan drug data base. Caudal appendage-deafness syndrome. ORPHA:1123

Caudal appendage-deafness syndrome is characterized by caudal appendage, short terminal phalanges, deafness, cryptorchidism, intellectual deficit, short stature and dysmorphism. It has been described in monozygotic twin boys. 